\title{
Variety in the Knowledge base of Knowledge Intensive Business
}

\section{Sectors}

\author{
Davide Consoli \\ Manchester Institute of Innovation Research (MIoIR), Manchester Business School (UK) \\ Institute of Innovation and Knowledge Management (INGENIO) CSIC-UPV, Valencia (Spain) \\ davide.consoli@mbs.ac.uk \\ Dioni Elche Hortelano \\ Faculty of Social Sciences, University of Castilla La-Mancha (Spain) \\ dioni.elche@uclm.es
}

\begin{abstract}
Knowledge Intensive Business Services (KIBS) are intermediary firms which specialize in knowledge screening, assessment and evaluation, and trade professional consultancy services. The remarkable rise of this broad class of activities is perceived by many as the natural by-product of modern knowledge economies within which increasing specialisation induces the need for professional agents in the markets for external knowledge. This paper addresses critically a conceptual flaw in the specialised literature which portrays KIBS as a homogeneous group of activities. Using official data on occupational information in the United States we observe and analyse high variety across KIBS sectors' occupational structures and skill requirements.
\end{abstract}

Keywords: Knowledge Intensive Business Sectors; Skill Intensity; Cross-Sectoral Variety

\section{Introduction}

Over the last decade the literature on innovation in services has grown rapidly within the field of innovation studies (Drejer, 2004; Miles, 2005; Consoli, 2007). This continuing effort elucidates the peculiarities of service activities, their progressively larger importance in modern economies and how these differ from manufacturing strictu sensu. From this sizeable body of empirical and theoretical research stems a strand dedicated exclusively to Knowledge Intensive Business Services (KIBS), that is, the intermediary firms specialized in knowledge screening, assessment and evaluation, and trading of professional consultancy services. This paper observes that while the addition of numerous empirical studies contributed to increase its scale, the literature on KIBS still fails to appreciate the assortment of cognitive and strategic architectures that can be observed within this diverse class of services. In spite of manifest differences between, say, Legal Activities and Data Processing, the majority of existing studies build upon and contribute to consolidate the implicit assumption that KIBS are a homogeneous clod (den Hertog and Bilderbeek, 2000; Tether, 2005). 
The demarcation between technology-intensive (T-KIBS) and management consulting activities, or personal services, (P-KIBS) was a staple of the pioneering work by Miles et al (1995). This conjecture received the support of empirical studies showing that KIBS sectors expand at different rates across countries due to differential propensity to specialize (Antonelli, 1998; Muller and Zenker, 2001; Freel, 2006; Zenker and Doloreux, 2008; Corrocher et al, 2009). The various revisions of the NACE classification further indicate that KIBS have grown diverse with the addition of subactivities and related specialties. By and large however the posture of these studies is the exception, not the norm within the specialised literature on KIBS. Overall, it should be noted, these signs of variety strike a chord with the ad-hoc nature of most, but not all, professional services which often escape easy standardisation, both conceptually and operationally. The development of problem-solving strategies around the task at hand for example is very common among P-KIBS. On the one hand this peculiar feature limits replicability across assignments and, a fortiori, across sectors; on the other hand the need to blend existing routines with new ones induces professional service firms to develop and accumulate a broad pool of complementary skills. This process of self-reinforcing variety is less pronounced in the context of TKIBS like machine maintenance, which instead thrive upon repetitive routines.

Taking the cue from this proviso the paper pursues two goals. First, with Malerba's (2005) work on the dynamics of sectoral systems of innovation as point of reference, is to appreciate the importance of within-industry heterogeneity and the extent to which task-complexity drives the breath and the depth of the skill-base. This conceptual frame shapes the second objective, assessing empirically the degree of heterogeneity across business services sectors using a rich data source on occupational information in the United States (U.S.). To the extent that individual knowledge is imperfectly reflected in the activities that make up any given sector, it is argued that problem-solving strategies stem from the application of a repertoire of skills to a specific task structure. To give empirical content to these notions we follow Autor et al (2003) by constructing a measure of skill intensity associated to each occupation; such an approach allows us to identify idiosyncratic characteristics in the occupational structures and the prevailing knowledge bases across KIBS sectors.

This paper is an exploratory exercise on the foretold themes as well as, to the best of our knowledge, a novel focus of analysis to capture cross-sectoral variety. It is 
structured as follows: section 2 reviews the literatures on the relationship between the growth of knowledge and the dynamics of industries and sectors, and on service innovation; section 3 analyses the skill requirements and the associated educational levels in KIBS sectors extracted from the official data on occupational information O*NET; the last Section summarizes and concludes.

\section{Variety and Innovation}

\section{1 - Background}

The field of innovation studies contributes significantly to advance understanding on industry evolution and on the intimate, yet elusive, connection between the growth of knowledge and the emergence, development and demise of activities within firms, firms within sectors, and so forth (Nelson, 1994; Malerba and Orsenigo, 1996; Antonelli, 2001; Metcalfe, 2002). Central to this tenet is the notion that industries and sectors grow as a result of increasing specialization in the prevailing activities; such a process entails the governance of different kinds of knowledge depending on the nature of latent opportunities as well as on available strategic routes (Antonelli, 2008). Under this perspective, argues Nelson (1991), 'representative’ firm views are illsuited to study the impact of varieties of micro-behaviours on sectors and industries. Another staple of innovation studies is that economic performance is contingent on context-specific circumstances. As Rosenberg (1976) remarks, sectors display significant variance in the ability to respond effectively to imbalances depending on the degree of competence by training and on the availability of dedicated pathways for the diffusion of experiential feedback. Building on these insights Malerba (2005) articulates innovation patterns according to sectoral specificities: sectors (2005: 385) are 'unified by some linked product groups for a given or emerging demand and which share some common knowledge. Firms in a sector have some commonalities and at the same time are heterogeneous'. The dynamics of sectors depend on the interdependencies across (i) the knowledge base; (ii) the key actors and the networks within which they operate; and (iii) the underpinning institutional infrastructure. The tenet of innovation studies posits that underpinning sectoral evolution stand two complementary dimensions of knowledge growth: first, the amount of stored information available for consultation expands as on-the-job experience is codified at least that part of experience which is amenable to codification; second, and most 
crucial, by encouraging diversification of problem-solving strategies the accumulation of experiential learning contributes to continually challenge sectoral and professional boundaries (Simon, 1969). In this sense knowledge growth and sectoral evolution are self-reinforcing processes (Metcalfe, 2002).

The processes of professionalization and systematization are important coordinating mechanisms for the growth of knowledge in industries and sectors. The former consists in the creation of routines aimed at facilitating the coordination of specialised activities (Savage, 1994); systematisation is the codification of skills by means of formal training and apprenticeship to favour the diffusion of novel routines (Rosenberg, 1976). The two processes are complementary in the sense that while professionalization promotes the emergence of heterogeneous but complementary routines, systematization facilitates transmission and adaptation of newly codified knowledge to different contexts of use. The professionalization of civil engineering, for example, entailed extracting operative principles from scientific knowledge (e.g. physical properties of materials) and combining these with experiential learning or "next-bench design" (e.g. reliance on the past experience of other engineers). After being codified in ways that others could understand and apply through own training and experience, routines could be transferred systematically to either sub-professions or to other domains, pending further adaptation (Feynman and Leighton, 1988, cited in Langlois and Savage, 2001).

Professionalization and systematization set off significant trajectories on the occupational structures and associated knowledge bases of sectors. The accumulation of experience reconfigures task structures so that business professionals, typically high-skilled white-collar workers, concentrate on core management activities while ancillary activities are assigned to support staff, either low-skilled white-collar or blue-collar workers (Langlois and Savage, 2001). Combined together division of labour and emergent variety in occupational structures induce the separation of demand for cognitive skills from that for non-cognitive skills. Autor et al (2003) recently drew attention to this phenomenon when observing the non-monotone impact of computerization on the demand for skills. In particular they note that the widespread adoption of ICTs induces (1) higher demand for cognitive and interpersonal skills, such as those used by educated professionals and managers (socalled abstract tasks); (2) lower demand for clerical and routine analytical and 
mechanical skills, such as those used in mid-level white collar and manufacturing production jobs (routine tasks); and (3) negligible impact on the demand for manual skills (manual tasks), such as those used in blue-collar service jobs.

To connect these dynamics with the conceptual frame outlined above, one can reasonably expect that in general as sectors evolve their core activities grow diverse and more specialised. At the same time the extent of task partitioning and correlated adaptations in the composition of the workforce and the skill base depend on the nature and the relative importance of problem-solving activities in each sector. This is especially true, as will be discussed in the remainder, for activities like professional services where the prevailing ecology of routines adapts over time to the changing demands of local interactions.

\section{2 - Service Innovation and KIBS}

A vast, and ever-growing, body of literature contributes our understanding of the main characteristics of service activities, in particular: their information-based nature and the associated dynamics related to Information and Communication Technologies; flexibility of services due to close interactions between providers and users; the fundamental role of human resources and skills in stimulating innovative responses among service firms (Miozzo and Soete, 2001; Tether, 2003; Drejer, 2004; Miles, 2005; Consoli, 2007). From this sizeable body of empirical and theoretical research stems a strand dedicated exclusively to Knowledge Intensive Business Services (KIBS), that is, intermediary firms which specialize in knowledge screening, assessment, evaluation, and trade their services in the form of consultancy. The label KIBS - originally coined by Miles et al (1995) for firms whose business is the creation, accumulation and dissemination of knowledge - inspired a fertile line of research (Zenker and Doloreux, 2008; Muller and Doloreux, 2009). By and large the emergence of KIBS is understood as physiological adaptation to progressively finer specialisation in economies with high levels of per capita income (Antonelli, 1998; Hipp, 1999; Den Hertog, 2000; Muller and Zenker, 2001; Kuuisto and Meyer, 2003; Pavitt, 2005; Castellacci, 2008). What is perhaps less debated is that the structure of knowledge is not isomorphic with respect to the organisation of business services. To be sure, innovation scholars insist that knowledge has no unambiguous meaning and focus on its heterogeneity and the multiple specific uses to which it can be applied. 
Ultimately, the mutual influence between the tasks established by production plans and the capabilities that are needed to accomplish them confers to knowledge its emergent structure (Langlois, 2001; Metcalfe, 2002).

KIBS rely heavily on tacit knowledge embodied in their employees as well as on codified knowledge, which is both input and output. The core competence common to all KIBS is the integration of different forms of knowledge into tradable output; however some KIBS do not suppose changes on the content of information but merely the maintenance of infrastructures for its transmission while other KIBS operate transformations with the goal of trading newly created information packages. The broader point is that some activities are more amenable than others to standardization like technical assistance type of services whose goals - e.g. correcting technical faults - and problem-solving routines - e.g. the sequence of steps that are needed to restore faulty machinery - are adequately specified by a closed menu of alternatives. In such cases the spectrum of available problem-solving options is known ex-ante with a fine degree of precision and reproduction of existing routines suffices. Other types of services are less amenable to standardization because the ability to formulate problem-solving strategies in these contexts depends closely on task-specific information which is hard to file among existing repertoires of learned solutions. This is typical of services which entail close client-supplier interaction like legal services, or marketing: in all such cases the task structure has a higher degree of indeterminacy compared to the former group and, accordingly, the information package that is traded in the market is the outcome of a problem-solving strategy which can only partially be worked out ex-ante.

On these premises it seems reasonable to expect that patterns of learning, occupational structures and the associated skill bases will differ to a great extent across and within the two macro-categories of business services. More professionally oriented P-KIBS strive to tailor solutions around clients' specific requirements; openness and networking are recurrent features in their business model, and so is the tight dependence on the knowledge and expertise of specific employees (Hitt et al, 2001; Muller and Zenker, 2001; Lowendhal et al, 2001; Kuuisto and Meyer, 2003). The typical task structure of this class of services entails a combination of general knowledge, practical problem-solving and on-the-job learning (Bettencourt et al., 2002; Miles 2005); the associated skill bases encompass cognitive skills such as 
creative response, critical thinking as well as social skills to achieve good comprehension of the problem at hand by to keeping close relations with the clients. It seems clear that this pattern of specialisation differs considerably from that of TKIBS, technical assistance-type of activities where the context of service provision is almost neutral for the supply of standardised service packages.

These remarks suggest a degree of variety across KIBS which the scholarly literature has a tendency to ignore. The seminal paper by Miles and co-authors (1995) separates technology-intensive services (T-KIBS) from traditional business and management consulting activities, or personal services (P-KIBS). A handful of empirical studies support this conjecture and show that KIBS sectors do not expand homogeneously across countries but, rather, feature differential sub-sectoral specialization (Antonelli, 1998; Muller and Zenker, 2001; Freel, 2006; Zenker and Doloreux, 2008; Corrocher et al, 2009). A cursory look at the NACE classification further suggests that KIBS have grown diverse over the last few years with the expansion of specialized subactivities. Overall this evidence is consistent with the main dictum of innovation studies that the patterns of resource use and development observed across firms and sectors differ depending on a mix of historical and institutional circumstances (Rosenberg, 1976; Nelson, 1991). Our contention is that the posture of the foretold studies is the exception, not the norm: by and large the specialised literature perpetuates the implicit assumption that KIBS are a homogeneous group of activities (den Hertog and Bilderbeek, 2000; Tether, 2005). Recognizing and addressing this gap is relevant to appreciate the assortment of strategic architectures that can be observed in KIBS sectors (Zenker and Doloreux, 2008) as well as the innovation patterns they generate (Amara et al, 2008; Corrocher et al, 2009). The remainder of the paper sets out to analyse the knowledge base of KIBS as captured by data on occupational structures and skill requirements.

\section{An empirical analysis of variety in the knowledge base of KIBS}

The foregoing discussion suggests that professional services escape easy standardisation, both conceptually and operationally. The tight coupling between client requirements and problem-solving strategies limits replicability across assignments and, a fortiori, across sectors. Since professionally-oriented P-KIBS blend existing routines with new ones, they need to coordinate heterogeneous 
repertoires of skills. This process of self-reinforcing variety is less pronounced in the context of T-KIBS, which instead thrive upon the application of repetitive routines most common in the area of technical assistance an information processing. The objective of this section is to propose an empirical strategy aimed at assessing the degree of heterogeneity across business services sectors.

The centrality of knowledge growth in the evolution of sectors and industries has already been emphasised in the preceding pages. To operationalise these insights let us recall that individual knowledge is imperfectly reflected in the activities that can be observed in any given sector (Richardson, 1971); accordingly, carrying out the tasks that make up those activities call for specific configurations of the workforce and of their skill base. Put another way, the organisation of the workforce and the pool of skills they possess reflect at any time the purposeful commitment of human resources towards the agreed production plans. Our proposition is that the idiosyncratic character of each sector and, by extension, the degree of diversity across different sectors can be captured well by looking at the repertoire of skills implicated by the prevailing occupational structure. Bearing in mind the theoretical framework outlined above this section seeks to address the following questions:

1. What occupational structures can be observed in each KIBS sector? And do these differ across such sectors?

2. What knowledge bases, as inferred from the demand for skills, prevail in each KIBS sector? To what extent do these differ across such sectors?

\section{1 - Methodology and Data Analysis}

The present study uses data from the survey on abilities 'Occupational Information Network' (O*NET) carried out by the US Department of Labour in 2007. The database contains standardized information on attributes and characteristics of occupations such as skills, level of training required and job-specific tasks. Respondents assign a score to each of the surveyed characteristics which serves as a basis to rank occupations according to their intensity or relative importance. ${ }^{1}$ For the purpose of the present analysis we will concentrate on the skill set included in O*NET

\footnotetext{
${ }^{1}$ The database was initiated in 2000 under the sponsorship of the US Department of Labor and the Employment and Training Administration. See http://www.onetcenter.org/overview.html; details about data collection available at: http://www.onetcenter.org/dataCollection.html. This paper use version 13.0 of O*NET published in 2008 (the latest full version available as of July 2009).
} 
shown in Table 1 and grouped in six macro-categories: Basic, Complex Problem Solving, Resource Management, Social, Systems and Technical Skills.

\section{TABLE 1 AROUND HERE}

The rationale of this dataset is that each occupation can be decomposed in sets of activities whose tasks and the associated repertoires of skills are ordered hierarchically. To the extent that individual knowledge is imperfectly reflected in the activities that make up any given sector, it is argued that occupations are mechanisms to coordinate particular repertoires of skills vis-à-vis specific task structures; put another way, occupations are considered as vectors of skill-task co-occurrences. Following Autor et al (2003) we sort the O*NET skills of Table 1 into four macrocategories: cognitive routinary, cognitive non-routinary, interactive and manual (see Appendix). The routine-non routine dichotomy is useful to the effect of capturing differences between activities that involve well-defined protocols, such as data inputting, as opposed to others that require creative ad-hoc responses like consultancy tasks, whose content cannot be fully specified ex-ante (see Howell and Wolff, 1992). ${ }^{2}$ The empirical analysis presented below seeks to compare occupational structures and levels of skill intensity across KIBS sectors which, for simplicity, are selected following Miles et al (1995) distinction between T-KIBS and P-KIBS ${ }^{3}$ (Table 2).

\section{TABLE 2 AROUND HERE}

Let us look at the occupational structures of KIBS sectors in Table 3 where sectors are ranked according to the educational requirement index (third column of Table 3). The latter is calculated on the basis of the Standard Vocational Preparation (SVP), that is, the average number of years in excess of High-School training that are necessary to be employed in each sector. After regrouping sectors this way we note a clear divide between those requiring lower level of training, such as Maintenance and repair of office or Other computer related activities, and those employing highly educated professionals such as R\&D and Market Research and Public Opinion Polling. The observation of these two blocks confirms the demarcation between Technology Intensive (T-KIBS) and Personal (P-KIBS) services anticipated by Miles and co-

\footnotetext{
${ }^{2}$ To clarify matters: the job of a bookkeeper scores high in routine skills; a technical assistant uses more intensively manual skills; a sales agent employs more interactive skills; managers carry out mainly non-routine cognitive and interactive skills; and so forth.

${ }^{3}$ See also Jones and Miles (2008) for an expanded classification of KIBS sectors.
} 
authors (1995), with two important exceptions: on the basis of these characteristics R\&D and Architectural services, originally included in the former group now cluster together with P-KIBS.

After having allocated occupations across all KIBS sectors using the Bureau of Labor Statistics ‘Occupational Employment Statistics' for $2007^{4}$, we compute the shares of Unskilled, Blue Collar and White Collar occupations (far-right columns of Table 3) and observe three main patterns: sectors with mostly low-skill occupations have the lowest average educational requirement; intermediate sectors dominated by highskilled blue collar and low-skill white collar occupations; and KIBS sectors in which white-collar managerial positions with high-level training and experience hold the lion share. The data also indicate strong demarcation between high- and low-level TKIBS, that is, between technical services that play a variably complex role in the business of creating and managing infrastructures for information transfer. In the upper part of the table stand P-KIBS together with those 'anomalous' T-KIBS, R\&D and Architectural \& Engineering services. Overall the data do not warrant the implicitly accepted view that KIBS are the exclusive camp of highly qualified professionals (Maister 1993; Sarvary 1999; Lowendhal et al., 2001).

\section{TABLE THREE AROUND HERE}

Let us now analyse the skill base of KIBS sectors by means of a simple illustrative exercise. O*NET data on the relative characteristics of occupations were used recently by Blinder (2009) and Kletzer and Jensen (2010) to measure skill intensity in studies of service off-shoring, and by Bacolod et al (2009) to estimate the impact of geographical agglomeration on the hedonic prices of worker skills. Following a similar logic, we seek to elaborate a comparable measure of skill intensity for each KIBS sector. ${ }^{5}$ To do so we aggregate the raw scores of skills across all occupations weighted by the importance assigned by survey respondents and, subsequently, compute four indexes per sector, one for each category of skills: Cognitive Routinary; Cognitive Non-Routinary; Interactive and Manual:

\footnotetext{
${ }^{4}$ http://www.bls.gov/OES/

${ }^{5}$ Two interesting approaches to the analysis of skill bases have been recently proposed by Neffke and Henning (2009) using data on labor flows across industries in Sweden, and by Giuri et al (2010) on Open Source Software developers.
} 
$S K j^{T}=\ln \left[\frac{\sum s^{T}{ }_{i, j}}{N_{j}} \varepsilon_{j}\right]$

where

$\mathrm{j}=1, \ldots, 15$ (sectors)

$\mathrm{i}=1, \ldots, \mathrm{n}(31<\mathrm{n}<64)$ occupations per sector (see third column in Table 3)

$\mathrm{N}_{\mathrm{j}}=\sum n j \quad$ (Tot. occupations per sector)

$s_{i, j}=$ score assigned to the skill by respondents

$\varepsilon_{j}=$ average years of education in excess of High School

T = Cogn_Routinary; Cogn_Non - Routinary; Interactive; Manual

The values of the skill intensity indexes are plotted in Figure 1 with KIBS sectors ordered by increasing levels of average educational requirement from left to right.

\section{FIGURE ONE ABOUT HERE}

The first indication is that skill intensity increases with the educational level over the sectors; in particular Cognitive, both routinary and non-, and Interactive grow steadily as we move to the far right of the diagram while Manual skills follow an opposite pattern. This should not be surprising since low-level ancillary services make more intensive use of Manual skills and relatively less of Interactive skills; the trend reverses in correspondence of intermediate KIBS such as Software Publishing and Database Activities - which mostly consist in supporting information management where predominant blue collar and white collar occupations (see Table 3) use more intensely Cognitive Routinary skills and progressively more Interaction skills. The divergence between Manual and non-Manual skills grows more as we move towards the P-KIBS block (marked with a P in the diagram), that is, sectors with highest shares of White Collar jobs and average educational levels. Although there is no single pattern, we observe the higher relative importance of Cognitive Non-Routinary skills - which score systematically higher than Routinary -and of Interactive skills, though with some oscillations.

Before concluding we run a simple statistical exercise to test differences in the distribution of skill types (Cognitive Routinary and Non-, Manual and Interactive) across sectors and between two sub-groups: T-KIBS versus P-KIBS, and sectors dominated by Blue-Collar versus White-Collar occupations. The tests in Table 4 confirm that the cross-sectoral distributions of each of the skill types differ at conventional statistical levels. 


\section{TABLE FOUR ABOUT HERE}

\section{2 - Discussion}

The results of this descriptive exercise lend support to the conjecture of diversity across KIBS sectors, and therefore resonate with the indications provided by previous studies that had been mentioned above (Antonelli, 1998; Muller and Zenker, 2001; Freel, 2006; Zenker and Doloreux, 2008; Corrocher et al, 2009). It should be emphasised that, besides common consensus on the centrality of knowledge as engine of economic development and diversity, all those studies, including our own, reach the same conclusion by taking different methodological routes. Such a posture is not shared by the bulk of specialised literature on KIBS. As Malerba (2005) warns, failure to account for diversity in the composition and organisation across sectors is a serious limit to understanding the autocatalytic nature of economic evolution.

The main message of the present study is that the configuration of the task structure determines the repertoires of skills which are called upon to formulate effective problem-solving strategies. This implies that contrary to what the existing literature maintains there is a high degree of variety across KIBS' skill bases and occupational structures. Borrowing Herbert Simon’s (1969) phrasing, we observe that in 'semantically-rich domains', like architecture or business consultancy, task-specific information stemming from the uniqueness of client-supplier relations is especially relevant for the formulation of problem-solving. The empirical analysis confirms that P-KIBS sectors are the reign of professionals whose discretion and cognitive ability is crucial in pursuing well-specified goals through imperfectly (e.g. non ex-ante) specified problem-solving strategies. The opposite holds true for non 'semanticallyrich' T-KIBS like technical assistance or maintenance where the task structure is more standardized and the degree of professional discretion is lower. In such instances, the core routines require mostly manual non-cognitive skills. The profiling proposed here indicates also that KIBS have evolved beyond the original classification of Miles et al (1995), with R\&D and Architectural \& Engineering services formerly classified as TKIBS sharing common features with P-KIBS for what concerns educational requirements, occupational structures and skill bases, as well as the existence of two sub-groups within the group of T-KIBS. 
By assigning prominence to the role of skills, the present study draws attention to the practical dimension of knowledge growth in the process of sectoral evolution. Innovation involves selective rejection of obsolete routines, searching for and experimental introduction of new ones. In the universe of professional services problem-solving strategies are constrained in a variety of ways by the capabilities of both the co-workers' and the clients'. The subgroup of P-KIBS, for example, engages dynamic production activities as they strive to translate requests for uncertain outcomes into tradable output; the data analysis shows that more complex forms of service provision entails blending standardized knowledge with instant comprehension of the particular features of the task at hand. These are instances of qualitative changes in 'the human agent as a factor of production' (Rosenberg, 1976) that a growing literature on the skills structures of sectors, industries and communities is beginning to address (Howell and Wolfe, 1992; Autor et al, 2003; Neffke and Henning, 2009; Giuri et al, 2010).

Before concluding it is worth reflecting on two challenges that arise from the present study. The fundamental role of variety for the sustainability of innovation calls for appropriate adaptations in the supply of education and training to keep up with shifting technological frontiers. This requires traditional investments on schools and universities but also expansion of vocational training to the effect of supporting both the diversification of skill base as well as the channels through which these are acquired (Levy and Murnane, 2004; Tether et al, 2005; Blinder, 2009). The adoption of such policies, in turn, implies a high degree of coherence among industry, learning institutions, communities of practice and, last but not least, labour markets (Nelson, 1994; Cohendet and Meyer-Krahmer, 2001).

Taking the cue from the last remark we further note that the present paper raises a conceptual challenge. For the purpose of the task at hand, the study of KIBS sectors, we borrowed concepts and language from other areas of social sciences, namely Labour Economics (Howell and Wolff, 1992; Autor et al, 2003; Levy and Murnane, 2004) and the Economics of Science (Stephan et al, 2004; 2007). This reminds us that rarely, if ever, innovation studies engage the mechanisms that regulate the availability of skills to sectors and firms. It seems therefore pertinent to ask: why does the labour market play such a small role, if any at all, in the tenet of innovation studies? This is not the place to belabour at length the point, but it seems appropriate to offer a short 
reflection. A recent review by Pianta (2004) shows that the mutual connections between employment and technological change go way back. At the same time the overriding inclination of the literature has made little headway beyond quantitative measurements of job displacement, and considerable gaps persist on issues that sit at the intersection of labour market dynamics and innovation: to name a few, the cumulative bias of existing knowledge bases on the direction of technological change; organisational consequences of changing modes of employment; the impact of income distribution on the incentives for investing in human-capital; and the adaptation of learning institutions for the systematization and diffusion of new knowledge. The notion of workforce as ensemble of individual forms of knowledge purported here will likely resonate with innovation scholars; under such a perspective labour markets could be understood as emergent forms for organizing knowledge rather than mere conduits for the allocation of given resources. Advancing these questions however requires a paradigm shift from equilibrium-based perspectives towards the integration of long-term processes of structural change. Only few steps have been made in this direction thus far (Caroli, 2001; Vona and Consoli, 2009) and the hope is that future work will set out to tackle such questions.

\section{Concluding remarks}

There are different analytical routes to analyse the composition of industries and sectors, such as the output they produce (products and innovations) or the inputs that are used (labor, capital, intermediate inputs). This paper takes the route less travelled by, in the hope that it will make some difference.

This study confirms that professional services escape easy standardisation, both conceptually and operationally. The core competence of combining different forms of knowledge to produce tradable output is common across all KIBS but, as Miles et al (1995) had anticipated, differences among these sectors are non negligible. The paper expands this point and argues that such a demarcation is most apparent when comparing KIBS whose chief business is the maintenance of infrastructures for the transmission of information with those that create and trade new information. In particular, it is stressed, the former thrive upon the application of repetitive routines while formulating problem-solving strategies around the task at hand is most common 
among the latter. Along these lines, it is suggested, a great deal of diversity will likely be observed in the prevailing occupational structures and skill bases.

The analysis of skill structures elucidates the learning processes that drive the growth and evolution of sectors; accordingly, the adaptation of the skill base dictated by changes in the nature of the prevalent knowledge is crucial for both the success and the failure of technological opportunities. Accounting for the different types of knowledge that make up occupations, activities and sectors is of paramount importance to come to grips with widely-debated phenomena such as skill mismatches and knowledge gaps. Methodologically the paper draws attention to a rich and hitherto little used data source with considerable potential well beyond the remit of studies on services sectors. The approach proposed here is appreciative and does not have pretence to employ objective measures but, rather, to explore alternatives. The authors are aware both of the importance of accounting for the contribution of knowledge inputs and, even more, of the perils of attempting to elaborate metrics. This can hardly be overstated. At the same time, however, there is scope to add new indicators that capture subtle aspects of knowledge growth and its ramifications in specific industrial contexts: survey data on skills like $\mathrm{O}^{*} \mathrm{NET}$, collected straight from the source, are a good place to start. ${ }^{6}$

Before concluding we should flag up that the analysis proposed here offers only a partial view of the co-evolution between occupational structures and the relevant skill bases. In fact, the answers emerging from this paper have raised new questions. For one, it is clear that the growth of knowledge is an incremental process whose character is best appreciated from a long-term perspective, and that such issues are best approached with the aid of longitudinal data rather than on individual years. Along this line, one of the questions that the authors seek to explore in the future is whether patterns of sectoral specialisation feature some kind of self-reinforcing bias, and whether this can be captured empirically by observing mutual adaptations between skill repertoires and task configurations over the long haul. But for the time being we hope to have provided a first hint in this direction.

\footnotetext{
${ }^{6}$ The survey data Sourceforge.net on Open Source developers is broadly similar. See Giuri et al (2010).
} 
Acknowledgements. We would like to thank the administrators of the National Center for O*NET Development for making data available. We are also grateful to Stan Metcalfe, Dick Nelson, Ian Miles, Marcela Miozzo, Damian Grimshaw, Ronnie Ramlogan, Shu-Li Cheng, Barbara Jones, Koen Frenken, Carolina Castaldi and Pablo D’Este Cukierman for helpful comments. Earlier drafts benefited from lively debates at the Manchester Institute of Innovation Research; the XIX International Conference of the European Association for REsearch on SERvices (RESER) in Budapest; and the IXI International Conference of the Asociación Científica de Economía y Dirección de la Empresa (ACEDE) in Toledo. The valuable insights of two anonymous referees and of the Editor helped to improve substantially the paper. Davide Consoli acknowledges financial support from the European Community (FP7PEOPLE-IEF-2008-235278). The usual caveats apply.

\section{Bibliographic references}

Amara, N., R. Landry and D. Doloreux (2009) "Patterns of Innovation in KnowledgeIntensive Business Services”. Service Industries Journal 29(4): 407-430.

Antonelli, C. (1998) "Localized technological change, new information technology and the knowledge and the knowledge-based economy: the European evidence". Journal of Evolutionary Economics 8: 177-198.

Antonelli, C. (2001) The Microeconomics of Technological Systems, Oxford: Oxford University Press.

Antonelli, C. (2008) Localized technological change: Towards the economics of complexity, Routledge, London and New York.

Autor, D., F. Levy and R. Murnane (2003) "The Skill Content of Recent

Technological Change: An Empirical Exploration”. Quarterly Journal of Economics 118: 1279-1333.

Bacolod, M., B. Blum and W.C. Strange (2009) "Urban Interactions: Soft Skills vs. Specialization”. Journal of Economic Geography 9(2): 227-262.

Bettencourt, L.A., A.L. Ostrom, S.W. Brown and R.I. Roundtree (2002) “Client CoProduction in Knowledge-Intensive Business Services”. California Management Review 44(4): 100-128.

Blinder, A.S. (2009) “Offshoring: Big Deal, or Business as Usual?”. In: J. Bhagwati, A.S. Blinder, B.M. Friedman Offshoring of American Jobs: What Response from U.S. Economic Policy? MIT Press.

Blinder, A.S. (2009) "Education for the Third Industrial Revolution” forthcoming in J. Hannaway and D. Goldhaber (eds) Creating a New Teaching Profession, Urban Institute Press.

Brynjolfsson, E. and L. Hitt (1997) "Information Technology, Organization, and Productivity: Evidence from Firm-level”. MIT Sloan School of Management Paper.

Caroli, E. (2001) "New Technologies, Organizational Change and the Skill Bias: What Do We Know?” In: P. Petit and L. Soete, (eds.) Technology and the Future of Employment in Europe. Edward Elgar. 
Castellacci, F. (2008) “Technological paradigms, regimes and trajectories:

manufacturing and service industries in a new taxonomy of sectoral patterns of innovation”. Research Policy 37 (6-7): 978-994.

Cohendet, P. and F. Meyer-Krahmer (2001) “The theoretical and policy implications of knowledge codification”. Research Policy 30(9): 1563-1591

Consoli, D. (2007) "Services and Systemic Innovation: a cross-sectoral perspective". Journal of Institutional Economics 3(1): 71-89.

Corrocher, N., L. Cusmano and A. Morrison (2009) "Modes of innovation in knowledge-intensive business services evidence from Lombardy”. Journal of Evolutionary Economics 19(2): 173-196.

David, P.A. (2001) “Understanding digital technology’s evolution and the path of measured productivity growth: Present and future in the mirror of the past". In: Brynolfsson, E., Kahin, B. (eds.) Understanding the Digital Economy, MIT Press.

Den Hertog, P. (2000) "Knowledge-intensive business services as co-producers of innovation”. International Journal of Innovation Management 4(4): 491-528.

Den Hertog, P. and R. Bilderbeek (2000) "The New Knowledge Infrastructure: the Role of Technology-Based Knowledge-Intensive Business Services in National Innovation Systems”. In: M. Boden and I. Miles (eds.) Services and the KnowledgeBased Economy. Continuum: London, New York.

Doloreux, D. and R. Shearmur (2008) "Exploring and comparing innovation patterns across different knowledge business services". Paper presented at the Workshop The Dynamics of Knowledge and Innovation in Knowledge-Intensive Industries. Collegio Carlo Alberto, Turin (Italy).

Drejer, I. (2004) "Identifying Innovation in Surveys of Services: a Schumpeterian Perspective”. Research Policy, 33: 551-562.

Feynman, R. P. [as told to Leighton, R.] (1988). What do you care what other people think? New York: Norton.

Freel, M. (2006) "Patterns of Technological Innovation in Knowledge Intensive Business Services”. Industry \& Innovation 13(3): 335-358.

Giuri, P., M. Ploner, F. Rullani, S. Torrisi (2010) "Skills, Division of Labor and performance in collective inventions: evidence from Open Source Software”. International Journal of Industrial Organization 28(1): 54-68.

Hipp, C. (1999) "Knowledge-intensive business services in the new mode of knowledge production”. Al\&Society 13: 88-106.

Hitt, M.A., L. Bierman, K. Shimizu and R. Kochhar (2001) "Direct and Moderating Effects of Human Capital on Strategy and Performance in Professional Service Firms: A Resource-Based Perspective”. Academy of Management Journal 44(1): 13-28.

Howell, D. and Wolff, E. (1992) "Technical change and the demand for skills by US industries”. Cambridge Journal of Economics 16: 128-146.

Jones, B. and Miles, I. (2008) "Services, innovation and skills: scoping and definitions report”. Report, Manchester Institute of Innovation Research, University of Manchester. Online at: http://prest.mbs.ac.uk/kisa 
Kletzer, L. and J. B. Jensen (2010) "Measuring Tradable Services and the Task Content of Offshorable Services Jobs”. In: K. Abraham, M. Harper, and J. Spletzer (eds.) Labor in the New Economy. Chicago: University of Chicago Press.

Kuusisto, J. and M. Meyer (2003) "Insights into services and innovation in the knowledge intensive economy”. Technology Review 134/2003, Tekes, Helsinki.

Langlois, R.N. (2001) “Knowledge, consumption, and endogenous growth”. Journal of Evolutionary Economics 11(1): 77-93.

Langlois, R.N. and D.A. Savage (2001) "Standards, Modularity, and Innovation: the Case of Medical Practice”. In: Path Dependence and Path Creation, ed. Raghu Garud and Peter Karnøe. Hillsdale, NJ: Lawrence Erlbaum.

Levy, F. and R.J. Murnane (2004) The new division of labor : how computers are creating the next job market . Russell Sage Foundation; Princeton University Press.

Lowendhal, B.R., O. Revang and S.M. Fosstenlokken (2001) "Knowledge and Value Creation in Professional Service Firms: A Framework for Analysis”. Human Relations 54(7): 911-931.

Maister, D. (1993) Managing Professional Service Firms. New York, Free Press.

Malerba, F. and L. Orsenigo (1996) "Schumpeterian Patterns of Innovations are Technology Specific”. Research Policy 25: 451-478.

Malerba, F. (2005) "Sectoral Systems: How and Why Innovation Differs Across Sectors”. In: J. Fagerberg, D. Mowery and R.R. Nelson (eds), The Oxford Handbook of Innovation, Oxford: Oxford University Press.

Metcalfe, J.S. (2002) “Knowledge of Growth and the Growth of Knowledge”. Journal of Evolutionary Economics 12: 3-15.

Miles I., N. Kastrinos, K. Flanagan, R. Bilderbeek, B. den Hertog, W. Huntink and M. Bouman (1995) "Knowledge-Intensive Business Services: Users, Carriers and Sources of Innovation”. European Innovation Monitoring System (EIMS), EIMS Publication No. 15, Luxembourg.

Miles, I. (2005) "Innovation in Services”. In J. Fagerberg, D. Mowery, and R.R. Nelson (eds), The Oxford Handbook of Innovation, Oxford: Oxford University Press.

Miles, I. (2008) "Patterns of innovation in service industries”. IBM Systems Journal 47(1): 115-128.

Miozzo, M. and L. Soete (2001) "Internationalisation of Services: a Technological Perspective”. Technological Forecasting and Social Change 67(2):159-185.

Muller, E. and A. Zenker (2001) "Business services as actors of knowledge transformation: the role of KIBS in regional and national innovation systems". Research Policy 30(9): 1501-1516.

Muller, E. and D. Doloreux (2009) "What we should know about knowledgeintensive business services (KIBS)”. Technology in Society 31(1): 64-72.

Neffke, F. and M.S. Henning (2009) "Skill-relatedness and firm diversification”. Max Planck Institute of Economics Evolutionary Economics Group, Papers on Economics and Evolution.

Nelson, R.R. (1991) “Why do firms differ, and how does it matter?”. Strategic Management Journal 12(2): 61-74. 
Nelson R.R. (1994) “The co-evolution of technology, industrial structure and supporting institutions”. Industrial and Corporate Change 3: 47-64.

Pavitt, K. (2005) “Innovation processes”. In: J. Fagerberg, D. Mowery and R.R. Nelson (eds), The Oxford Handbook of Innovation, Oxford: Oxford University Press.

Pianta, M. (2004) “Innovation and employment”. In: I. Fagerberg, D. Mowery and R.R. Nelson, (eds.) The Oxford Handbook of Innovation. Oxford University Press.

Richardson, G.B. (1972) “The Organisation of Industry”. Economic Journal 82(327): 883-896.

Rosenberg, N. (1976) Perspectives on Technology. Cambridge University Press.

Salter, A. and B.S. Tether (2006) "Innovation in Services: Through the Looking Glass of Innovation Studies”. Advanced Institute of Management (AIM) Paper.

Sarvary, M. (1999) "Knowledge Management and Competition in the Consulting Industry”. California Management Review 41(2): 95-107.

Savage, D.A. (1994) "The professions in theory and history: the case of pharmacy". Business and Economic History 23 (2): 130-160.

Simon, H.A. (1969) The Sciences of the Artificial. MIT Press, Cambridge, Mass.

Stephan, P., A. Sumell, G. Black and J. Adams (2004) "Firm Placements of New PhDs: Implications for Knowledge Transfer”. In: D. Fornahl, C. Zellner and D. Audretsch (eds.) Role of Labour Mobility and Informal Networks for Knowledge Transfer. Springer.

Stephan, P., G. Black and T. Chaing (2007) "The Small Size of the Small Scale Market: The Early-Stage Labor Market for Highly Skilled Nanotechnology Workers”. Research Policy 36(6): 887-892.

Tether, B.S. (2003) "The sources and aims of innovation in services: variety between and within sectors”. Economics of Innovation and New Technologies 12(6):481-505.

Tether, B.S. (2005) "Do services innovate (differently)? Insights from the European Innobarometer Survey”. Industry and Innovation 12(2): 153-184.

Tether, B.S., A. Mina, D. Consoli and D. Gagliardi (2005) “The relationship between Innovation and Skills: a literature review”. Report to the Department of Trade and Industry (DTI, UK).

Vona, F. and D. Consoli (2009) "Innovation, Human Capital and Earning Distribution: Towards a dynamic life-cycle approach”. SENTE Working Paper, University of Tampere (Finland).

Zenker, A. and D. Doloreux (2008) “KIBS, perceptions and innovation patterns". International Journal of Service and Technology Management 10(2/3/4): 337-342. 


\begin{tabular}{|c|c|}
\hline I. Basic Skills & IV. Social Skills \\
\hline Active Learning & Coordination \\
\hline Active Listening & Instructing \\
\hline Critical Thinking & Negotiation \\
\hline Learning Strategies & Persuasion \\
\hline Mathematics & Service Orientation \\
\hline Monitoring & Social Perceptiveness \\
\hline \multicolumn{2}{|l|}{ Reading Comprehension } \\
\hline Science & V. Systems Skills \\
\hline Speaking & \multirow{4}{*}{$\begin{array}{l}\text { Judgment and Decision Making } \\
\text { Systems Analysis } \\
\text { Systems Evaluation }\end{array}$} \\
\hline Writing & \\
\hline & \\
\hline II. Complex Problem Solving Skills & \\
\hline \multirow[t]{2}{*}{ Complex Problem Solving } & VI. Technical Skills \\
\hline & Equipment Maintenance \\
\hline III. Resource Management Skills & Equipment Selection \\
\hline Management of Financial Resources & Installation \\
\hline Management of Material Resources & Operation and Control \\
\hline Management of Personnel Resources & Operation Monitoring \\
\hline \multirow[t]{6}{*}{ Time Management } & Operations Analysis \\
\hline & Programming \\
\hline & Quality Control Analysis \\
\hline & Repairing \\
\hline & Troubleshooting \\
\hline & Technology Design \\
\hline
\end{tabular}




\begin{tabular}{l|l|c}
\hline $\begin{array}{c}\text { NACE } \\
\text { Code }\end{array}$ & Traditional KIBS Sectors & $\begin{array}{c}\text { KIBS } \\
\text { Type }\end{array}$ \\
\hline 72.1 & Hardware consultancy & T-KIBS \\
72.5 & Maintenance and repair of office, accounting and computing machinery & T-KIBS \\
72.21 & Publishing of software & T-KIBS \\
72.22 & Other software consultancy and supply & T-KIBS \\
72.3 & Data processing & T-KIBS \\
72.4 & Database activities & T-KIBS \\
72.6 & Other computer related activities & T-KIBS \\
73 & R\&D & T-KIBS \\
74.11 & Legal activities & P-KIBS \\
74.12 & Accounting, book-keeping and auditing activities; tax consultancy & P-KIBS \\
74.13 & Market research and public opinion polling & P-KIBS \\
74.4 & Advertising & P-KIBS \\
74.14 & Business and management consultancy activities & P-KIBS \\
74.2 & Architectural and engineering activities and related technical consultancy & T-KIBS \\
74.3 & Technical testing and analysis & T-KIBS \\
\hline
\end{tabular}

Table 2: Traditional KIBS Sectors 


\begin{tabular}{|c|c|c|c|c|c|c|c|c|}
\hline & \multirow[b]{2}{*}{ KIBS Type } & \multirow{2}{*}{$\begin{array}{c}\text { Average } \\
\text { Educational } \\
\text { Requirement }\end{array}$} & \multirow[b]{2}{*}{$\begin{array}{c}\text { Total N } \\
\text { Occupations }\end{array}$} & \multirow[b]{2}{*}{ Unskilled } & \multicolumn{2}{|c|}{ Blue Collar } & \multicolumn{2}{|c|}{ White Collar } \\
\hline & & & & & $\begin{array}{c}\text { Low } \\
\text { Skilled }\end{array}$ & $\begin{array}{c}\text { High } \\
\text { Skilled }\end{array}$ & $\begin{array}{c}\text { Low } \\
\text { Skilled }\end{array}$ & $\begin{array}{c}\text { High } \\
\text { Skilled }\end{array}$ \\
\hline $\mathrm{R} \& \mathrm{D}$ & T-KIBS & 5.44 & 39 & 1 & 1 & 5 & 35 & 58 \\
\hline Market research and public opinion polling & P-KIBS & 5.23 & 64 & 1 & 3 & 5 & 37 & 54 \\
\hline Business and management consultancy activities & P-KIBS & 4.65 & 47 & 2 & 2 & 12 & 35 & 49 \\
\hline Architectural and engineering activities & T-KIBS & 4.54 & 48 & & 9 & 15 & 29 & 47 \\
\hline Legal activities & P-KIBS & 4.21 & 34 & & 9 & 18 & 33 & 40 \\
\hline Advertising & P-KIBS & 4.18 & 31 & 3 & 9 & 16 & 38 & 34 \\
\hline Accounting. book-keeping, auditing and tax consultancy & P-KIBS & 3.74 & 44 & 3 & 7 & 30 & 38 & 22 \\
\hline Hardware consultancy & T-KIBS & 3.73 & 51 & & 21 & 27 & 34 & 18 \\
\hline Other software consultancy and supply & T-KIBS & 3.37 & 60 & 7 & 16 & 38 & 27 & 12 \\
\hline Database activities & T-KIBS & 3.2 & 48 & 2 & 16 & 34 & 39 & 9 \\
\hline Publishing of software & T-KIBS & 3.18 & 36 & 5 & 13 & 33 & 39 & 10 \\
\hline Technical testing and analysis & T-KIBS & 2.99 & 42 & 8 & 22 & 31 & 30 & 9 \\
\hline Data processing & T-KIBS & 2.86 & 42 & 9 & 33 & 29 & 22 & 7 \\
\hline Other computer related activities & T-KIBS & 2.58 & 38 & 11 & 29 & 36 & 19 & 5 \\
\hline Maintenance and repair of office and machinery & T-KIBS & 2.13 & 64 & 9 & 36 & 30 & 22 & 3 \\
\hline
\end{tabular}

Table 3: Details of educational requirements, occupational volume and structure (\%) by KIBS sector 


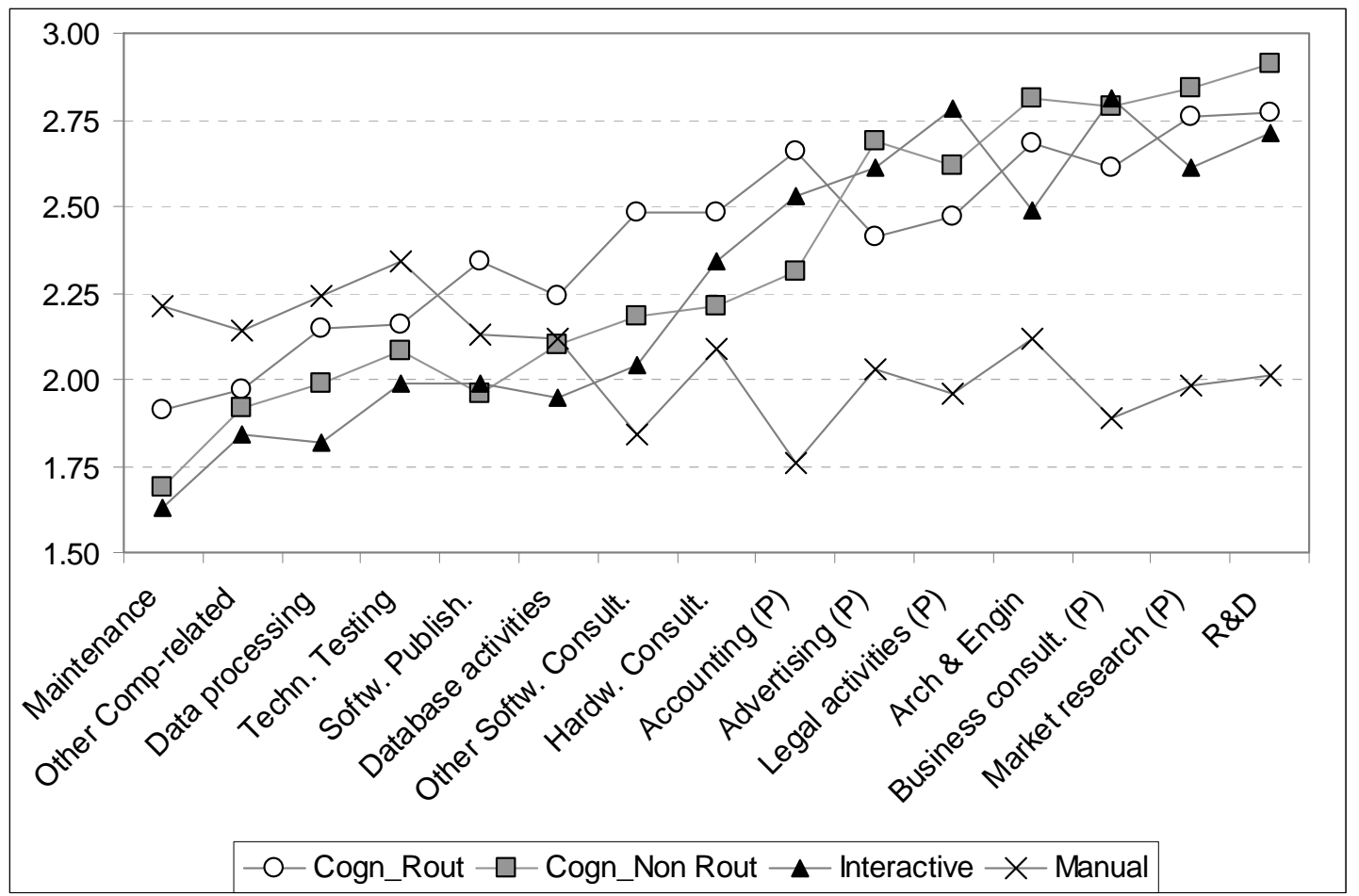

Figure 1. Skill Intensity across KIBS sectors (P=P-KIBS) 


\begin{tabular}{lc|cc}
\hline & ANOVA & \multicolumn{2}{c}{ Independent samples t-test } \\
\hline & All KIBS & T_KIBS-P_KIBS & Blue_Coll-White_Coll \\
\hline & F Statistic & t Statistic & t Statistic \\
\hline Routine Cognitive & $36.008^{* * *}$ & $12.897^{* * *}$ & $8.227^{* * *}$ \\
Non Routine Cognitive & $52.807^{* * *}$ & $12.685^{* * *}$ & $8.688^{* * *}$ \\
Interactive & $29.008^{* * *}$ & $9.231^{* * *}$ & $7.116^{* * *}$ \\
Manual & $18.391^{* * *}$ & $10.086^{* * *}$ & $7.775^{* * *}$ \\
\hline \multirow{2}{*}{$* * *$ Significance at $1 \%$ level } & & \\
\hline
\end{tabular}

Table 4: Significance test for differences within and across KIBS groups 


\begin{tabular}{ll}
\hline Skill & Skill_Type \\
\hline Active Learning & Cognitive Non-Routinary \\
Active Listening & Cognitive Non-Routinary \\
Complex Problem Solving & Cognitive Non-Routinary \\
Coordination & Cognitive Non-Routinary \\
Critical Thinking & Cognitive Non-Routinary \\
Judgment and Decision Making & Cognitive Non-Routinary \\
Learning Strategies & Cognitive Non-Routinary \\
Reading Comprehension & Cognitive Non-Routinary \\
Monitoring & Cognitive Routinary \\
Speaking & Cognitive Routinary \\
Writing & Cognitive Routinary \\
Equipment Selection & Cognitive Routinary \\
Management of Financial Resources & Cognitive Routinary \\
Management of Material Resources & Cognitive Routinary \\
Management of Personnel Resources & Cognitive Routinary \\
Mathematics & Cognitive Routinary \\
Operation Monitoring & Cognitive Routinary \\
Operations Analysis & Cognitive Routinary \\
Programming & Cognitive Routinary \\
Quality Control Analysis & Cognitive Routinary \\
Science & Cognitive Routinary \\
Systems Analysis & Cognitive Routinary \\
Systems Evaluation & Cognitive Routinary \\
Technology Design & Cognitive Routinary \\
Time Management & Cognitive Routinary \\
Troubleshooting & Cognitive Routinary \\
Instructing & Interactive \\
Negotiation & Interactive \\
Persuasion & Interactive \\
Service Orientation & Interactive \\
Social Perceptiveness & Interactive \\
Equipment Maintenance & Manual \\
Installation & Manual \\
Operation and Control & \\
Repairing & \\
\hline & \\
& Manual \\
\hline
\end{tabular}

